\title{
Regressed coronary ostial stenosis in a young female with Takayasu arteritis: a case report
}

\author{
Tetsuro Yokokawa ${ }^{1,2^{* \dagger}} \mathbb{D}$, Hiroyuki Kunii ${ }^{1 \dagger}$, Takashi Kaneshiro', Shohei Ichimura', Akiomi Yoshihisa ${ }^{1,3}$, \\ Makiko Yashiro Furuya ${ }^{4}$, Tomoyuki Asano ${ }^{4}$, Kazuhiko Nakazato ${ }^{1}$, Takafumi Ishida ${ }^{1}$, Kiyoshi Migita ${ }^{4}$ and \\ Yasuchika Takeishi ${ }^{1}$
}

\begin{abstract}
Background: Takayasu arteritis is a rare systemic vasculitis, which affects the aorta and its major branches, especially in young females. Diagnosis and treatment for Takayasu arteritis with coronary stenosis are important to prevent fatal complications. Immunosuppressive treatment such as corticosteroid is a common treatment for this condition. However, the effects of immunosuppressive treatment on inflammatory coronary stenosis caused by Takayasu arteritis remains unknown.

Case presentation: An 18-year-old female had chest oppression on effort and was referred to our hospital due to ST-segment depression in $\mathrm{I}, \mathrm{a} \mathrm{V}_{\mathrm{L}}$, and $\mathrm{V}_{2-4}$ on electrocardiogram. Coronary angiography showed severe stenosis in the ostium of both the left main trunk and the right coronary artery. ${ }^{18}$ F-fluorodeoxyglucose (FDG) positron emission tomography/computed tomography showed isolated inflammation of the aortic root. She was diagnosed with Takayasu arteritis and treated with combined immunosuppressive treatment with corticosteroid and tocilizumab, which decreased the FDG uptake in the aortic root. Four months after initiation of the immunosuppressive treatment, coronary angiography showed regression of the coronary ostial stenosis. Coronary artery bypass surgery was considered, but the patient rejected invasive revascularization for coronary artery disease. She did not have chest oppression or ST-segment depression after the immunosuppressive treatment. She had no cardiac events for 6 months after discharge.
\end{abstract}

Conclusions: We described regressed coronary ostial stenosis in a young female patient with Takayasu arteritis. Immunosuppressive treatment might have a favorable effect on coronary ostial stenosis in Takayasu arteritis.

Keywords: Takayasu arteritis, Coronary ostial stenosis, Regression, Tocilizumab, ${ }^{18} \mathrm{~F}$-fluorodeoxyglucose positron emission tomography/computed tomography, Case report

\section{Background}

Takayasu arteritis is a rare disease that typically occurs in young females, affecting the aortic arch and proximal branches of the aorta, as well as pulmonary arteries. The incidence rate of coronary artery disease in Takayasu arteritis is 10 to $45 \%$ in autopsy cases $[1,2]$. Coronary

\footnotetext{
* Correspondence: yokotetu@fmu.ac.jp

${ }^{\dagger}$ Tetsuro Yokokawa and Hiroyuki Kunii contributed equally to this work.

'Department of Cardiovascular Medicine, Fukushima Medical University, 1 Hikarigaoka, Fukushima, Fukushima 960-1295, Japan

2Department of Pulmonary Hypertension, Fukushima Medical University,

Fukushima, Japan

Full list of author information is available at the end of the article
}

artery stenosis is due to the extension of the inflammatory process and intimal proliferation in the ascending aorta. Seventy-three percent of occlusive coronary artery diseases are localized around the coronary ostium, and coronary artery stenosis is sometimes fatal $[1,2]$. ${ }^{18} \mathrm{~F}$-fluorodeoxyglucose (FDG) positron emission tomography (PET)/computed tomography $(\mathrm{CT})$ is widely used for malignant and inflammatory diseases, by which we can detect active vasculitis and monitor disease activity [3]. ${ }^{18} \mathrm{~F}$-FDG PET/CT is also useful for evaluating inflammatory coronary lesions.

(c) The Author(s). 2019 Open Access This article is distributed under the terms of the Creative Commons Attribution 4.0 International License (http://creativecommons.org/licenses/by/4.0/), which permits unrestricted use, distribution, and reproduction in any medium, provided you give appropriate credit to the original author(s) and the source, provide a link to the Creative Commons license, and indicate if changes were made. The Creative Commons Public Domain Dedication waiver (http://creativecommons.org/publicdomain/zero/1.0/) applies to the data made available in this article, unless otherwise stated. 
For the treatment of Takayasu arteritis, prednisolone has been used in 79 to $94 \%$ of patients to control disease activity $[4,5]$. Among biologic drugs, tocilizumab, an anti-interleukin-6 receptor antibody, has been reported to be effective for the treatment of refractory Takayasu arteritis [6]. The effectiveness of the immunosuppressive treatment, including prednisolone and tocilizumab, is unknown for inflammatory coronary arterial lesions. One anecdotal report described the regression of coronary artery stenosis evaluated by CT after immunosuppressive treatment [7]. Among invasive revascularization techniques, percutaneous coronary intervention with coronary stent has a high risk of restenosis [8]. For patients with severe coronary artery stenosis, coronary artery bypass surgery is considered after suppression of disease activity $[9,10]$. There is no established treatment for coronary arterial lesions for favorable long-term prognosis in young patients with Takayasu arteritis. We present a rare case of a young female with Takayasu arteritis who had regressed coronary ostial stenosis after immunosuppressive treatment and was evaluated by repeated coronary angiography and ${ }^{18} \mathrm{~F}$-FDG PET/CT.

\section{Case presentation}

An 18-year-old female suffered from chest oppression on effort for a month. She visited a hospital, and her electrocardiogram showed ST-segment depression in leads $\mathrm{I}, a V_{\mathrm{L}}$, and $\mathrm{V}_{2-4}$ (Fig. 1a). She was suspected of having angina pectoris, and was referred to our hospital. Her laboratory data on admission showed a normal range of creatinine kinase and troponin I as shown in Table 1. Echocardiography revealed normal left ventricular contraction and mild to moderate aortic regurgitation. Coronary angiography showed severe stenosis in the ostium of both the left main trunk and the right coronary artery (Fig. 2a, b). Quantitative coronary angiography analysis was performed with a computerized quantitative analysis system (QAngio XA version 7.3, Medis Medical Imaging System, Leiden, The Netherlands), using a contrast-filled catheter as a calibration source. The percentage of the diameter of the most severe stenosis compared with the reference diameter was defined as \% diameter stenosis [11]. \% diameter stenosis of the ostial stenosis was $95.0 \%$ in the left main trunk and $87.2 \%$ in the right coronary artery. Intra-coronary administration of isosorbide dinitrate did not dilate the coronary ostial stenosis, suggesting that the stenosis was an organic lesion. Optimal medical treatment, including beta-blocker, antiplatelet, and statin, was initiated for her coronary artery disease. Contrast-enhanced CT showed no specific abnormality of the aorta (Fig. 3a, b). She did not have renal artery stenosis or hypertension. Her right and left ankle-brachial indices were 1.08 , and 1.03 , respectively. She was examined by an ophthalmologist and did not have vision impairment. Magnetic resonance angiography revealed no significant

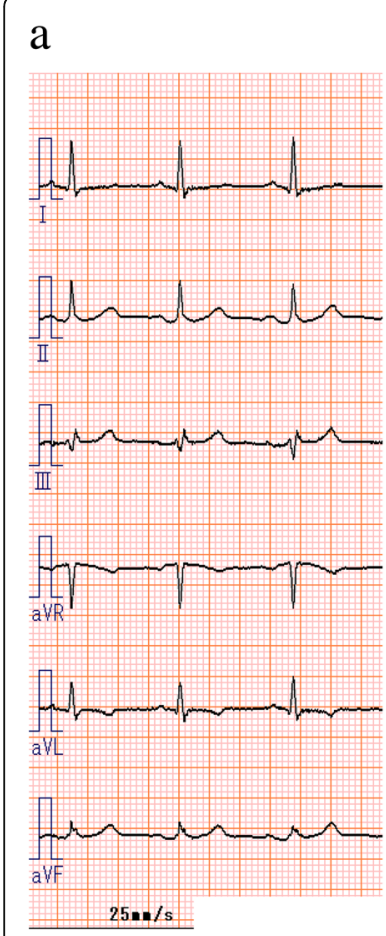

b
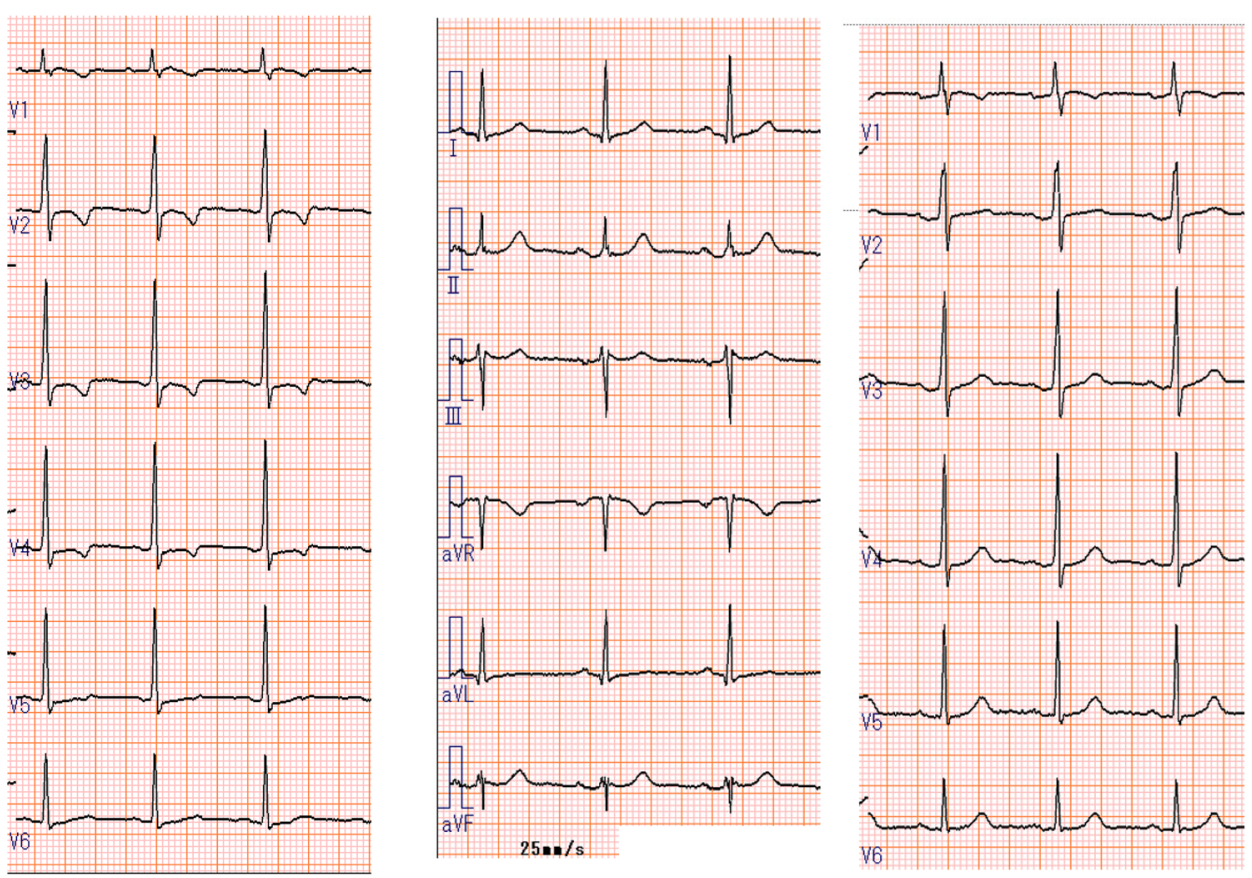

Fig. 1 Electrocardiogram. a. Electrocardiogram showed ST-segment depression in leads I, aV $V_{L}$, and $V_{2-4}$. b. Electrocardiogram showed no STsegment depression after the treatment 
Table 1 Laboratory findings on admission

\begin{tabular}{|c|c|}
\hline Parameters & Value \\
\hline \multicolumn{2}{|l|}{ Blood count } \\
\hline White cell count & $10,100 / \mu \mathrm{L}$ \\
\hline Red blood cell & $451 \times 10^{4} / \mu \mathrm{L}$ \\
\hline Hemoglobin & $12.0 \mathrm{~g} / \mathrm{dL}$ \\
\hline Hematocrit & $37.1 \%$ \\
\hline Platelet count & $37.4 \times 10^{4} / \mu \mathrm{L}$ \\
\hline \multicolumn{2}{|l|}{ Biochemistry } \\
\hline AST & $16 \mathrm{IU} / \mathrm{L}$ \\
\hline ALT & $13 \mathrm{IU} / \mathrm{L}$ \\
\hline LDH & $248 \mathrm{IU} / \mathrm{L}$ \\
\hline ALP & $275 \mathrm{IU} / \mathrm{L}$ \\
\hline Total bilirubin & $0.7 \mathrm{mg} / \mathrm{dL}$ \\
\hline Direct bilirubin & $<0.1 \mathrm{mg} / \mathrm{dL}$ \\
\hline BUN & $9 \mathrm{mg} / \mathrm{dL}$ \\
\hline Creatinine & $0.71 \mathrm{mg} / \mathrm{dL}$ \\
\hline eGFR & $91 \mathrm{~mL} / \mathrm{min} / 1.73 \mathrm{~m}^{2}$ \\
\hline Sodium & $141 \mathrm{mEq} / \mathrm{L}$ \\
\hline Potassium & $4.4 \mathrm{mEq} / \mathrm{L}$ \\
\hline Chlorine & $103 \mathrm{mEq} / \mathrm{L}$ \\
\hline Total protein & $7.4 \mathrm{~g} / \mathrm{dL}$ \\
\hline Albumin & $3.4 \mathrm{~g} / \mathrm{dL}$ \\
\hline Uric acid & $5.0 \mathrm{mg} / \mathrm{dL}$ \\
\hline Creatine kinase & $54 \mathrm{IU} / \mathrm{L}$ \\
\hline CK-MB & $<0.5 \mathrm{IU} / \mathrm{L}$ \\
\hline Troponin I & $0.035 \mathrm{ng} / \mathrm{mL}$ \\
\hline BNP & $10.2 \mathrm{pg} / \mathrm{mL}$ \\
\hline Triglyceride & 143 mg/dL \\
\hline $\mathrm{HDL}-\mathrm{C}$ & $39 \mathrm{mg} / \mathrm{dL}$ \\
\hline LDL-C & $111 \mathrm{mg} / \mathrm{dL}$ \\
\hline CRP & $2.13 \mathrm{mg} / \mathrm{dL}$ \\
\hline FT3 & $2.81 \mathrm{pg} / \mathrm{mL}$ \\
\hline FT4 & $1.32 \mathrm{ng} / \mathrm{mL}$ \\
\hline TSH & $3.510 \mathrm{U} / \mathrm{mL}$ \\
\hline Glucose & $109 \mathrm{mg} / \mathrm{dL}$ \\
\hline HbA1c (NGSP) & $5.5 \%$ \\
\hline ESR (1 h) & $40 \mathrm{~mm}$ \\
\hline SAA & $479 \mu \mathrm{g} / \mathrm{mL}$ \\
\hline
\end{tabular}

AST aspartate transaminase, $A L T$ alanine aminotransferase, $A L P$ alkaline phosphatase, $B N P$ B-type natriuretic peptide, BUN blood urea nitrogen, $C R P C$ reactive protein, $C K-M B$ creatine kinase $M B$, eGFR estimate glomerular filtration rate, ESR erythrocyte sedimentation rate, FT3 free triiodothyronine, FT4 free thyroxine, $H b A 1 c$ hemoglobin $A 1 c, H D L-C$ high-density lipoprotein, $L D H$ lactate dehydrogenase, LDL-C low-density lipoprotein, SAA serum amyloid A, TSH thyroid stimulating hormone, NGSP national glycohemoglobin standardization program stenosis of her carotid artery. The patient had no coronary risk factors or signs of infectious disease and congenital heart disease. C-reactive protein, serum amyloid A, and erythrocyte sedimentation rate $(1 \mathrm{~h})$ on admission were $2.13 \mathrm{mg} / \mathrm{dL}$ (normal range: $0.00-0.30 \mathrm{mg} / \mathrm{dL}$ ), $479 \mu \mathrm{g} / \mathrm{mL}$ (normal range: $0.0-8.0 \mu \mathrm{g} / \mathrm{mL}$ ), and $40 \mathrm{~mm}$ (normal range: 3-15 mm), respectively, suggesting systemic inflammation.

${ }^{18} \mathrm{~F}-\mathrm{FDG}$ PET/CT showed isolated inflammation of the aortic root (Fig. 4a, b). She was therefore diagnosed with Takayasu arteritis, and oral administration of prednisolone was started from $0.56 \mathrm{mg} / \mathrm{kg} /$ day. Tocilizumab was added 3 months after the initiation of prednisolone (Fig. 5). Follow-up coronary angiography showed regression of the ostial stenosis 4 months after the initiation of prednisolone, and \% diameter stenosis was $86.7 \%$ in the left main trunk and $72.6 \%$ in the right coronary artery (Fig. 2c, d). Intravascular ultrasound or optical coherence tomography was not performed for the ostial lesions. Her C-reactive protein and erythrocyte sedimentation rate $(1 \mathrm{~h})$ were decreased to $0.03 \mathrm{mg} / \mathrm{dL}$ and $5 \mathrm{~mm}$, respectively. The second ${ }^{18}$ F-FDG PET/CT showed decreased ${ }^{18}$ F-FDG uptake in the aortic root, but still showed inflammation (Fig. 4c, d). Her serum amyloid A of $13.8 \mu \mathrm{g} / \mathrm{mL}$ was not normalized, therefore we decided to control the disease activity by combined immunosuppressive treatment including steroid pulse therapy (methylprednisolone $1 \mathrm{~g} /$ day for 3 days). Oral methotrexate ranging from 4 to $8 \mathrm{mg} /$ week was administered to decrease corticosteroid dose (Fig. 5). The levels of serum amyloid A were not significantly increased and the dose of prednisolone was decreased from 0.28 to $0.21 \mathrm{mg} / \mathrm{kg} /$ day after administration of methotrexate.

Myocardial perfusion imaging with ${ }^{13} \mathrm{~N}$-ammonia PET detected myocardial ischemia (Fig. 6). Coronary artery bypass surgery was considered after the suppression of disease activity, but the patient and her family rejected invasive revascularization for coronary artery disease. After immunosuppressive treatment with prednisolone, tocilizumab and methotrexate, chest oppression and ST-segment depression was not observed (Fig. 1b). She was discharged after a 201-day hospitalization and administered $0.21 \mathrm{mg} / \mathrm{kg} /$ day of prednisolone, $8 \mathrm{mg} /$ week of methotrexate, $162 \mathrm{mg} /$ week of tocilizumab, $40 \mathrm{mg} /$ day of isosorbide dinitrate, $15 \mathrm{mg} /$ day of nicorandil, $100 \mathrm{mg} /$ day of aspirin, $2.5 \mathrm{mg} /$ day of rosuvastatin, and $10 \mathrm{mg} /$ day of carvedilol. Electrocardiogram at rest revealed no significant ST-T change, and laboratory data showed no significant increase of C-reactive protein, erythrocyte sedimentation rate $(1 \mathrm{~h})$, or serum amyloid $\mathrm{A}$ in the ambulatory follow-up. She had no cardiac events for 6 months after discharge.

\section{Discussion and conclusions}

In the present case, coronary ostial stenosis of Takayasu arteritis was regressed after immunosuppressive treatment 


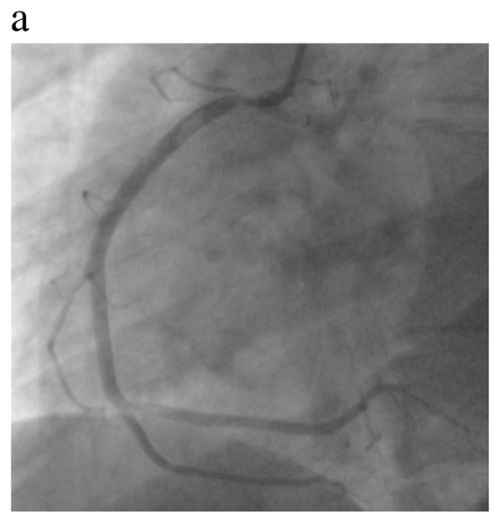

b

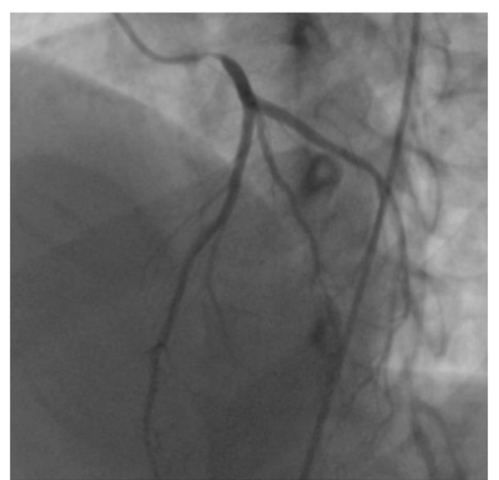

$\mathrm{C}$

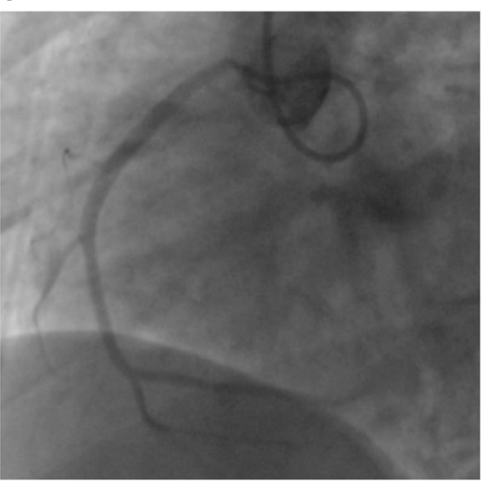

d

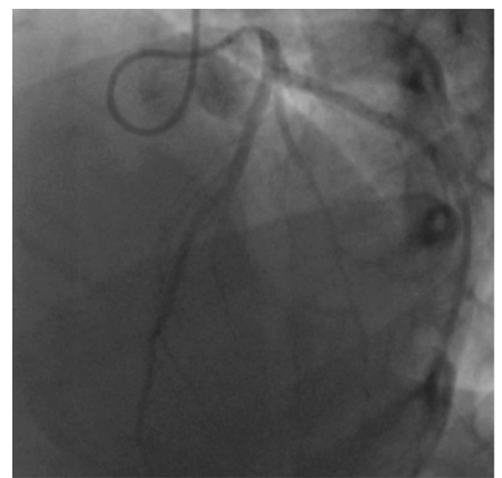

Fig. 2 Coronary angiography. $\mathbf{a}, \mathbf{b}$. Initial coronary angiography showed severe stenosis in the ostium of both the left main trunk and the right coronary artery. $\mathbf{c}$, d. Four months after immunosuppressive treatment, coronary angiography showed significant regression of the right coronary ostial stenosis, but limited regression of the left coronary ostial stenosis

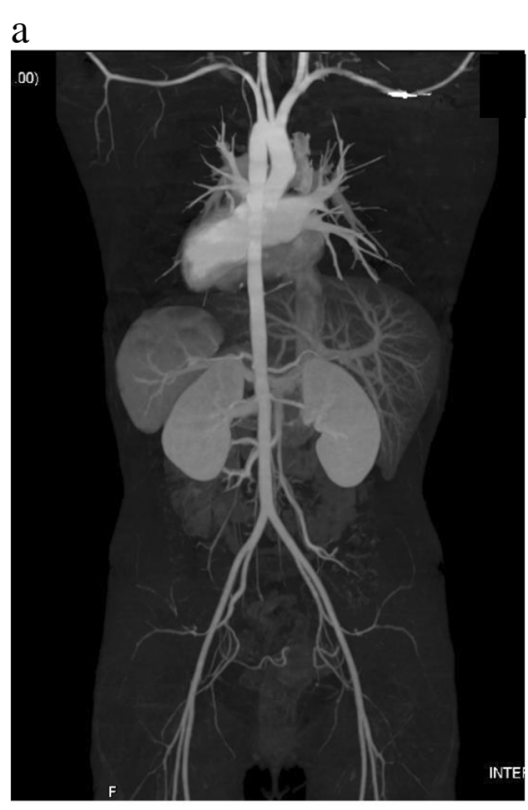

b

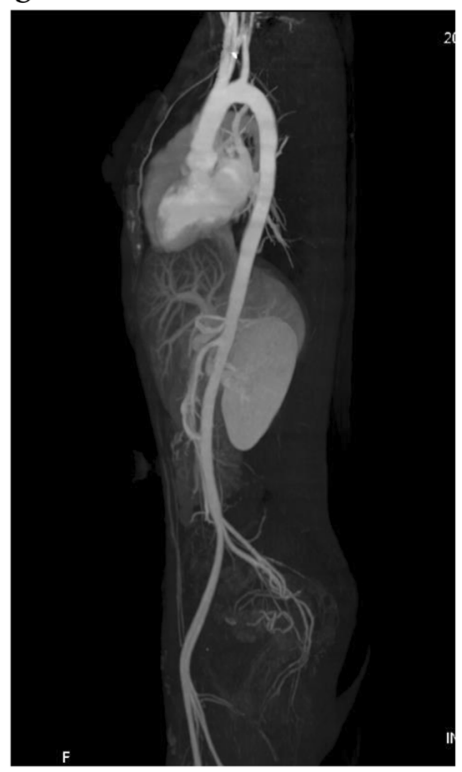

Fig. 3 Contrast-enhanced computed tomography. $\mathbf{a}$, b. No significant aortic lesion was detected by contrast-enhanced computed tomography 


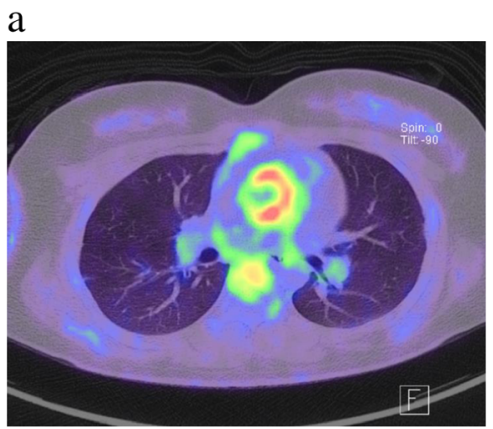

$\mathrm{b}$

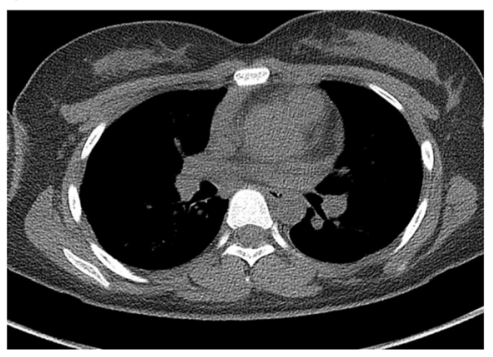

C

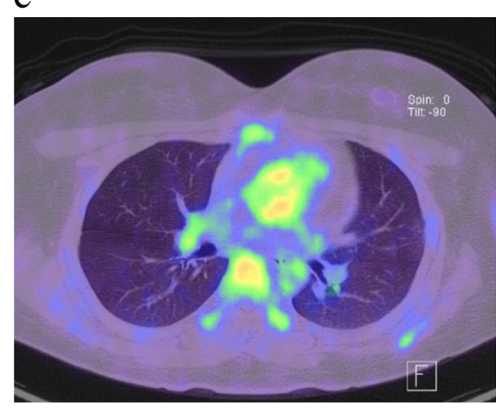

$\mathrm{d}$

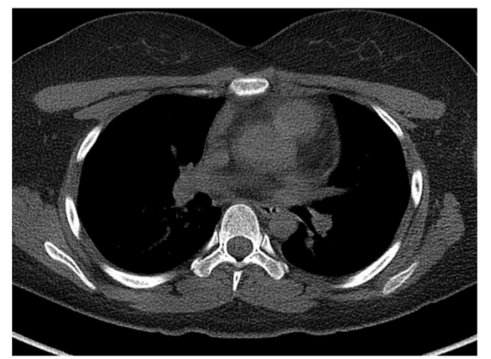

Fig. $4{ }^{18}$ F-fluorodeoxyglucose (FDG) positron emission tomography (PET)/computed tomography (CT). a, b. ${ }^{18}$ F-FDG PET/CT showed isolated inflammation of the aortic root on admission. The maximum standardized uptake value (max SUV) was 6.3. c, $\mathbf{d}$. After immunosuppressive treatment, ${ }^{18}$ F-FDG PET/CT showed decreased ${ }^{8}$ F-FDG uptake in the aortic root. The max SUV was decreased to 4.3

in accordance with the improvement of the inflammation evaluated by repeated ${ }^{18} \mathrm{~F}$-FDG PET/CT. This case suggests that inflammatory coronary stenosis might be reversible, and we could avoid early invasive revascularization for coronary artery disease in a case of active Takayasu arteritis. In our previous paper, we have focused only on the diagnosis using PET/Magnetic resonance imaging with ${ }^{18}$ F-FDG [12].

Because of the wide variation of clinical course, the diagnosis and management of Takayasu arteritis are still challenging [13, 14]. The effects of immunosuppressive

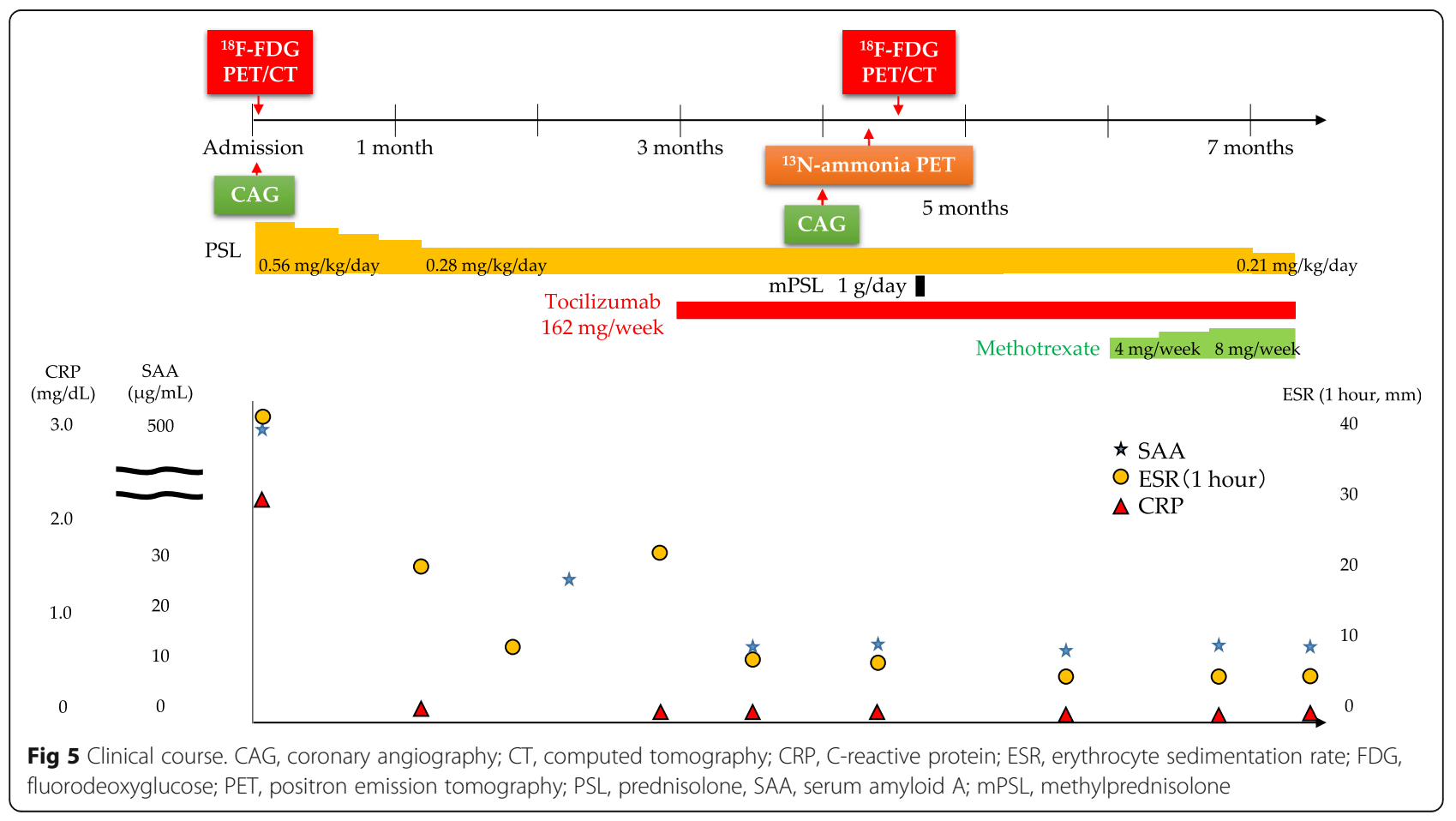




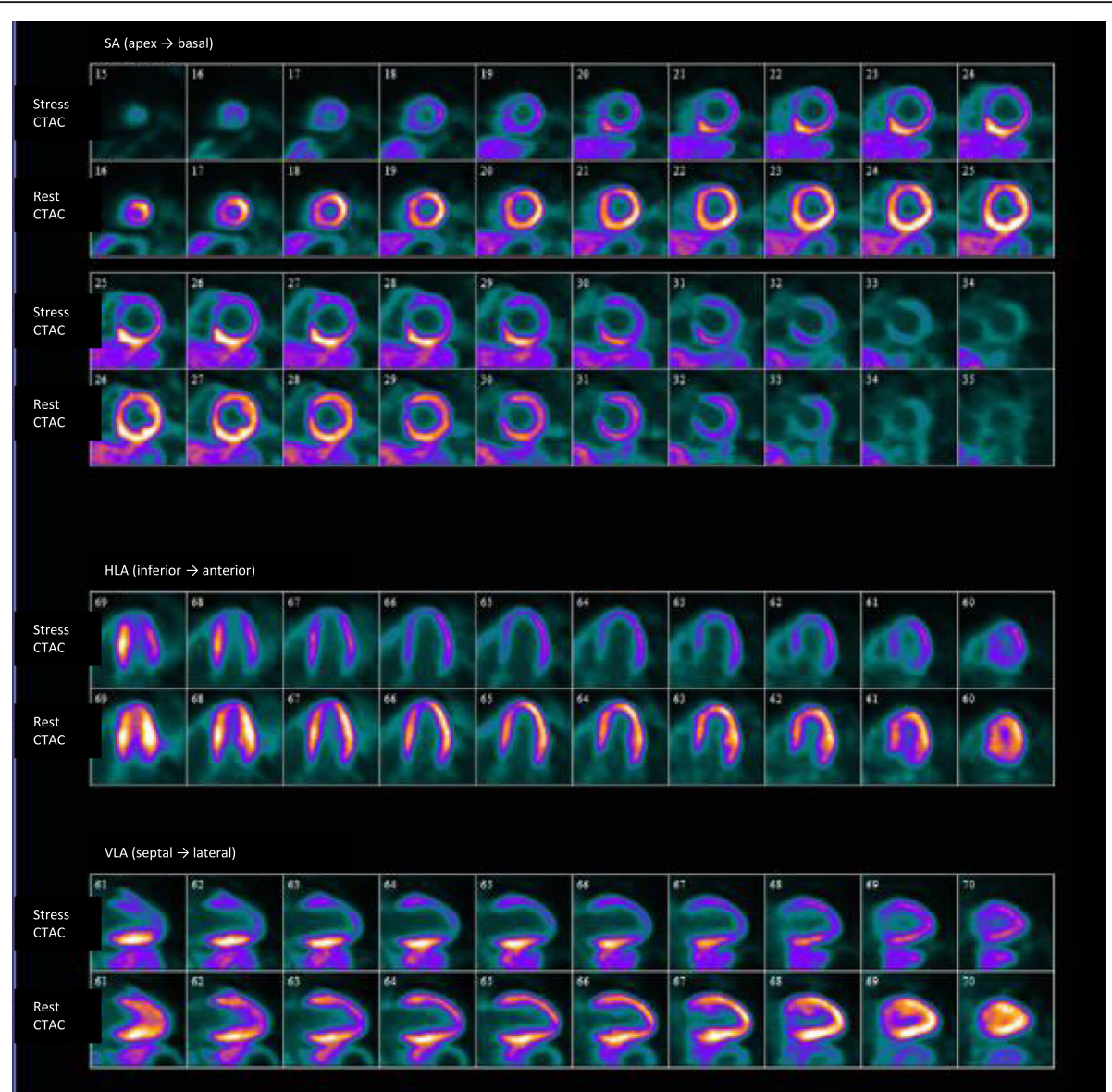

Fig. 6 Myocardial perfusion imaging with ${ }^{13} \mathrm{~N}$-ammonia positron emission tomography. Stress and rest ${ }^{13} \mathrm{~N}$-ammonia perfusion imaging demonstrated significantly decreased uptake in the anterior and lateral lesions and slightly decreased uptake in the inferior lesion. CTAC, computed tomography-based attenuation correction; HLA, horizontal long axis; SA, short axis; VLA, vertical long axis

treatment on inflammatory coronary stenosis caused by Takayasu arteritis remain unknown. Several previous case reports showed that arterial stenosis could be reversible in patients with Takayasu arteritis. Carotid artery stenosis has been reported to regress after corticosteroid therapy [15]. Immunosuppressive treatment improved stenotic lesions of the aorta in a case of a 3-month-old girl [16]. Regression of renal artery stenosis and abdominal aortic lesions has been reported after prednisolone treatment $[17,18]$. In cases with coronary stenosis, only two anecdotal reports described regression in Takayasu arteritis. Isomatsu et al. described regression of coronary ostial stenosis after steroid therapy and coronary artery bypass surgery [19]. Mohan et al. reported regressed coronary ostial stenosis with images from cardiac-gated CT after immunosuppressive treatment [7]. To our knowledge, the present case report is the first to show regressed coronary ostial stenosis using repeated coronary angiography and ${ }^{18} \mathrm{~F}$-FDG PET/CT.

In the present case, we performed early ${ }^{18}$ F-FDG PET/ $\mathrm{CT}$, and corticosteroid therapy was initiated immediately after the diagnosis of Takayasu arteritis. Early diagnosis and treatment might be effective to prevent the progression of active coronary artery disease in patients with Takayasu arteritis. There are several blood inflammatory biomarkers such as C-reactive protein and erythrocyte sedimentation rate. C-reactive protein is produced in the liver in response to interleukin-6, and thus C-reactive protein is not suitable to evaluate inflammatory activity after initiation of tocilizumab. However, serum amyloid $\mathrm{A}$ is suitable to evaluate disease activity under tocilizumab treatment $[20,21]$. In the present case, serum amyloid $\mathrm{A}$ and ${ }^{18} \mathrm{~F}$-FDG uptake indicated that inflammation remained in the patient. So, the treatment with methylprednisolone and methotrexate was started. The measurement of serum amyloid A was useful for managing Takayasu arteritis with coronary ostial stenosis under tocilizumab treatment.

Myocardial perfusion imaging detected myocardial ischemia caused by residual stenosis in our case. Follow-up angiography revealed more significant regression of the ostial lesion of the right coronary artery than that of the 
left coronary artery, and myocardial perfusion imaging showed only a slightly decreased uptake in the inferior wall. In the case of the left coronary artery, the ostial lesion showed limited regression at the follow-up angiography, and myocardial perfusion imaging revealed significant reversible uptake in the anterior and lateral wall.

In conclusion, we described regressed coronary ostial stenosis in a young female with Takayasu arteritis. Immunosuppressive treatment might have a favorable effect on coronary ostial stenosis in Takayasu arteritis.

\section{Abbreviations}

CT: Computed tomography; FDG: Fluorodeoxyglucose; PET: Positron emission tomography

\section{Acknowledgements}

We would like to thank all the members of the Department of

Cardiovascular Medicine in Fukushima Medical University.

\section{Funding}

None.

\section{Availability of data and materials}

Data are available from Tetsuro Yokokawa (e-mail: yokotetu@fmu.ac.jp) upon reasonable request and with permission of Fukushima Medical University Hospital.

\section{Authors' contributions}

Study design: TY and YT. Collection and interpretation of data: HK, TK, SI, AY, MYF, KN, TI, and KM. Manuscript writing: TY, TA and YT. All authors have read and approved the final manuscript.

\section{Ethics approval and consent to participate}

This study was approved by the ethics committee of Fukushima Medical

University and written informed consent was provided by the patient.

\section{Consent for publication}

Consent for publication was obtained by the patient in written form.

\section{Competing interests}

Tetsuro Yokokawa belongs to a department supported by Actelion Pharmaceuticals Japan Ltd. Akiomi Yoshihisa belongs to a department supported by Fukuda Denshi Co, Ltd. These companies are not associated with the contents of this study. No other authors have competing interests associated with this study.

\section{Publisher's Note}

Springer Nature remains neutral with regard to jurisdictional claims in published maps and institutional affiliations.

\begin{abstract}
Author details
'Department of Cardiovascular Medicine, Fukushima Medical University, 1 Hikarigaoka, Fukushima, Fukushima 960-1295, Japan. ²Department of Pulmonary Hypertension, Fukushima Medical University, Fukushima, Japan. ${ }^{3}$ Department of Advanced Cardiac Therapeutics, Fukushima Medical University, Fukushima, Japan. ${ }^{4}$ Department of Rheumatology, Fukushima Medical University, Fukushima, Japan.
\end{abstract}

Received: 2 December 2018 Accepted: 24 March 2019

Published online: 02 April 2019

\section{References}

1. Amano J, Suzuki A. Coronary artery involvement in Takayasu's arteritis. Collective review and guideline for surgical treatment. J Thorac Cardiovasc Surg. 1991;102:554-60.

2. Nagata S. Present state of autopsy cases of Takayasu's arteritis (aortitis syndrome) in Japan. J Jpn Coll Angiol. 1990;30:1303-8.
3. Tezuka D, Haraguchi G, Ishihara T, Ohigashi H, Inagaki H, Suzuki J, Hirao K, Isobe M. Role of FDG PET-CT in Takayasu arteritis: sensitive detection of recurrences. JACC Cardiovasc Imaging. 2012;5:422-9.

4. Ohigashi $H$, Haraguchi $G$, Konishi M, Tezuka D, Kamiishi T, Ishihara T, Isobe M. Improved prognosis of Takayasu arteritis over the past decade-comprehensive analysis of 106 patients. Circ J. 2012;76:1004-11.

5. Numano F, Okawara M, Inomata H, Kobayashi Y. Takayasu's arteritis. Lancet. 2000;356:1023-5.

6. Mekinian A, Comarmond C, Resche-Rigon M, Mirault T, Kahn JE, Lambert M, Sibilia J, Neel A, Cohen P, Hie M, Berthier S, Marie I, Lavigne C, Anne Vandenhende M, Muller G, et al. Efficacy of biological-targeted treatments in Takayasu arteritis: multicenter, retrospective study of 49 patients. Circulation. 2015:132:1693-700.

7. Mohan S, Poff S, Torok KS. Coronary artery involvement in pediatric Takayasu's arteritis: case report and literature review. Pediatr Rheumatol Online J. 2013;11:4.

8. Furukawa $Y$, Tamura T, Toma M, Abe M, Saito N, Ehara N, Taniguchi $R$, Nakagawa $Y$, Kita T, Kimura T. Sirolimus-eluting stent for in-stent restenosis of left main coronary artery in takayasu arteritis. Circ J. 2005;69:752-5.

9. Saadoun D, Lambert M, Mirault T, Resche-Rigon M, Koskas F, Cluzel P, Mignot C, Schoindre Y, Chiche L, Hatron PY, Emmerich J, Cacoub P. Retrospective analysis of surgery versus endovascular intervention in Takayasu arteritis: a multicenter experience. Circulation. 2012;125:813-9.

10. Wang X, Dang A, LV N, Cheng N, Cheng X, Yang Y, Song Y. Long-term outcomes of coronary artery bypass grafting versus percutaneous coronary intervention for Takayasu arteritis patients with coronary artery involvement. Semin Arthritis Rheum. 2017:47:247-52.

11. Reiber JH, Serruys PW, Kooijman CJ, Wijns W, Slager CJ, Gerbrands JJ, Schuurbiers JC, den Boer A, Hugenholtz PG. Assessment of short-, medium-, and long-term variations in arterial dimensions from computer-assisted quantitation of coronary cineangiograms. Circulation. 1985;71:280-8.

12. Takeishi Y, Kiko T, Yokokawa T, Kunii H, Ichimura S, Takizawa S, Masuda A, Kaneshiro T, Ando T, Takenoshita S. Takayasu arteritis detected by PET/MRI with (18) F-fluorodeoxyglucose. J Nucl Cardiol. 2018.

13. Kim ESH, Beckman J. Takayasu arteritis: challenges in diagnosis and management. Heart. 2018;104:558-65.

14. Strachan RW. The natural history of Takayasu's arteriopathy. Q J Med. 1964; 33:57-69.

15. Ishikawa K, Yonekawa Y. Regression of carotid stenoses after corticosteroid therapy in occlusive thromboaortopathy (Takayasu's disease). Stroke. 1987;18:677-9.

16. Liu H, Sun L, Upadhyaya RS, Chen Y, Ajoje OO. Case report: Takayasu arteritis in a 3-month-old Chinese girl. Medicine (Baltimore). 2018;97:e12637.

17. Wiggelinkhuizen J, Cremin BJ, Cywes S. Spontaneous recanalization of renal artery stenosis in childhood Takayasu arteritis: a case report. S Afr Med J. 1980;57:96-8.

18. Kulkarni TP, D'Cruz IA, Gandhi MJ, Dadhich DS. Reversal of renovascular hypertension caused by nonspecific aortitis after corticosteroid therapy. Br Heart J. 1974;36:114-6.

19. Isomatsu Y, Hoshino S, Tsukui H, Hara M, Nishiya Y, Ishikawa T. Regression of left main coronary ostium stenosis after surgical revascularization and steroid therapy. Jpn J Thorac Cardiovasc Surg. 2000;48:594-6.

20. Nair AM, Goel R, Hindhumati M, Jayakanthan K, Visalakshi J, Joseph G, Danda S, Danda D. Serum amyloid a as a marker of disease activity and treatment response in Takayasu arteritis. Rheumatol Int. 2017;37:1643-9.

21. Koga T, Nishino Y, Makiyama J, Hayashida T, Miyashita T, Izumi Y, Tamai M, Kawakami A, Equchi K, Migita K. Serum amyloid a is a useful marker to evaluate the disease activity of Takayasu's arteritis. Rheumatol Int. 2010;30:561-3. 